\title{
AVALIAÇÃO DE HÍBRIDOS DE SORGO PARA SILAGEM POR MEIO DA DEGRADABILIDADE IN SITU
}

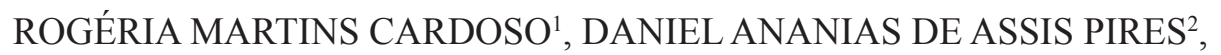 \\ VICENTE RIBEIRO ROCHA JÚNIOR ${ }^{2}$, SIDNEI TAVARES DOS REIS², \\ ELEUZA CLARETE JUNQUEIRA SALES ${ }^{2}$, DORISMAR DAVID ALVES ${ }^{2}$, LUCIANA CASTRO \\ GERASSEV ${ }^{3}$, JOSÉ AVELINO SANTOS RODRIGUES ${ }^{4}$ e LUCIANA OLIVA BARBOSA LIMA 5
}

${ }^{1}$ Mestre em Zootecnia, Unimontes (Campus Janaúba), Janaúba, MG, Brasil, rogymartins@yahoo.com.br

${ }^{2}$ Professor (a), Unimontes (Campus Janaúba), Janaúba, MG, Brasil, piresdaa@gmail.com, rochajuniorvr@hotmail.com, sidnei.reis@ unimontes.br,ecjsales@ibest.com.br,dorismar.alves@unimontes.br

${ }^{3}$ Professora, UFMG (Campus Montes Claros), Montes Claros, MG, Brasil, lgeraseev@gmail.com

${ }^{4}$ Pesquisador, Embrapa Milho e Sorgo, Sete Lagoas, MG, Brasil, avelino@cnpms.embrapa.br

${ }^{5}$ Mestranda em Zootecnia, Unimontes (Campus Janaúba), Janaúba, MG, Brasil, lucianaoliva@zootecnista.com.br

$\overline{\text { Revista Brasileira de Milho e Sorgo, v.11, n.1, p. 106-114, } 2012}$

\begin{abstract}
RESUMO - O experimento foi realizado com o objetivo de avaliar a degradabilidade in situ e a cinética de degradação da Matéria Seca (MS) e Proteína Bruta (PB) das silagens de três genótipos de sorgo. Foram utilizados duas linhagens isogênicas de sorgo granífero (CMSXS 114 e CMSXS 165) e um híbrido de sorgo (BR 700 duplo propósito). O plantio dos genótipos foi realizado no verão de 2009, em canteiros de $5 \mathrm{~m}$ de comprimento, $3 \mathrm{~m}$ de largura e espaçamento de $75 \mathrm{~cm}$ entrelinhas. Após o corte, o material foi ensilado. Após a abertura dos silos, as amostras foram pré-secas, moídas e acondicionadas em frascos de vidro para análises de MS e PB e a digestibilidade in situ destas frações. O delineamento experimental utilizado foi o inteiramente casualizado, com quatro repetições e quatro tratamentos, e as médias comparadas pelo teste de Tukey ao nível de 5\% de significância. Quanto à taxa de degradação da MS, a silagem da linhagem CMSXS165 sem tanino foi superior a todos os tratamentos. O genótipo da linhagem isogênica sem tanino (CMSXS 165) apresentou maior degradabilidade efetiva da PB do que a linhagem com tanino (CMSXS 114). Os resultados encontrados neste experimento permitem concluir que a presença do tanino pode reduzir a degradabilidade ruminal da MS e PB.
\end{abstract}

Palavras-chave: forragem, valor nutricional.

\section{EVALUATION OF HYBRID SORGHUM FOR SILAGE THROUGH IN SITU DEGRADABILITY}

\begin{abstract}
The experiment was carried out in order to evaluate in situ degradability and the degradation kinetics of dry matter, crude protein, neutral detergent fiber and acid detergent fiber of silages of three sorghum genotypes. Two isogenic lines of grain sorghum (CMSXS 114 and CMSXS 165) and one sorghum hybrid (double purpose, BR-700) were used. The plantation of the genotypes was carried out in summer/2009, in seedbeds $5 \mathrm{~m}$ long, $3 \mathrm{~m}$ wide and 0.75 $\mathrm{m}$ row spacing. After cutting, the material was ensilaged. After the opening of the silos the samples were pre-dried, milled and stored in glass bottles for analyses of dry matter, crude protein, neutral detergent fiber, acid detergent fiber, hemicelluloses, cellulose and lignin, $\mathrm{pH}, \mathrm{NH} 3 / \mathrm{NT}$ and in situ digestibility of the dry matter. An entirely randomized experimental design was used, with four replications and four treatments, and the means were compared by the Tukey test at 5\% significance. As for degradation rate of DM, the ensilage of CMSXS165 line without tannin was superior to all of the treatments. The isogenic line genotype without tannin (CMSXS 165) presented greater effective degradability of CP than the line with tannin (CMSXS 114). Thus, the results found in this experiment allow concluding that the presence of tannin can reduce the rumen degradability of the dry matter and crude protein of the ensilages.
\end{abstract}

Key words: forage, nutritional value. 
Em função da grande competitividade do mercado e da necessidade de se produzir, cada vez mais, leite e carne de qualidade, o uso de tecnologias para intensificar o sistema de produção torna-se fundamental.

Entretanto, a estacionalidade da produção de forragem na maior parte do Brasil pode ser considerada uma das principais causas dos baixos índices zootécnicos da pecuária no nosso país. Diante disso, a ensilagem surge como uma medida adotada pelos produtores para minimizar os efeitos estacionais na produção de alimento.

Neste contexto, diversas gramíneas podem ser utilizadas para produção de silagens. Dentre elas, o sorgo se destaca por ser uma planta adaptada ao processo de ensilagem devido às suas características fenotípicas que determinam facilidade de plantio, manejo, colheita e armazenamento, aliadas ao alto valor nutritivo, à alta concentração de carboidratos solúveis, essenciais para uma adequada fermentação lática, bem como aos altos rendimentos de massa seca por unidade de área (Neumann et al., 2002).

Mas, apesar das vantagens citadas anteriormente, o sorgo pode apresentar em sua composição compostos fenólicos resultantes do seu metabolismo secundário. Dentre estes compostos, podem ser citados os ácidos fenólicos, os flavonóides e os taninos. Os taninos podem formar complexos com as proteínas dietéticas ou com as proteínas da mucosa digestiva, aumentando, assim, as perdas de proteína endógena. $\mathrm{O}$ mesmo pode ocorrer em compostos como a celulose, a hemicelulose, a pectina, o amido e as saponinas. Já os efeitos in vivo são a diminuição na digestibilidade da proteína e da fibra em detergente neutro, o menor aproveitamento do nitrogênio, a diminuição do consumo voluntário e dos indicadores de produção (diminuições na produção de leite, no crescimento e no ganho de peso) (Cabral Filho, 2004).

O objetivo desde trabalho foi avaliar a degradabilidade in situ e a cinética de degradação da matéria seca e da proteína bruta das silagens de três genótipos de sorgo.

O sorgo foi cultivado nas dependências do CNPMS (Centro Nacional de Pesquisa de Milho e Sorgo), localizada no Km 45 da rodovia MG 424, em Sete Lagoas, MG, Brasil. As coordenadas geográficas são $19^{\circ} 28^{\prime}$ latitude Sul e longitude $44^{\circ} 15^{\prime}$ 08' WGrW. O clima da região, segundo Koopen, é do tipo AW (clima de savana com inverno seco).

Foram avaliados três tipos de sorgo, sendo duas linhagens isogênicas de sorgo granífero (CMSXS 114 e CMSXS 165) e um híbrido de sorgo (BR 700 duplo propósito).

O plantio dos genótipos foi realizado em novembro de 2009, em canteiros de $5 \mathrm{~m}$ de comprimento, $3 \mathrm{~m}$ de largura e espaçamento de $75 \mathrm{~cm}$ entrelinhas. A adubação constou de $350 \mathrm{~kg}$ de 8-28-16 no plantio e, após 40 dias, $110 \mathrm{~kg}$ de ureia na cobertura.

Para ensilagem, foram utilizadas apenas as duas fileiras centrais, quando cada genótipo apresentou um teor de matéria seca adequado ao processo. Foram utilizados 24 silos de laboratório feitos com tubos de PVC de $100 \mathrm{~mm}$ de diâmetro e $500 \mathrm{~mm}$ de comprimento, sendo a forrageira picada em picadeira estacionária e prensada com soquete de madeira.

Os silos foram vedados, no momento da ensilagem, com tampas de PVC providas de válvulas tipo Bunsen, lacradas com fita crepe, sendo pesados antes e após a ensilagem. Foram feitas seis repetições por tratamento e duas réplicas por parcela, sendo confeccionado um total de 24 silos, que foram abertos após 56 dias de ensilagem. 
As análises bromatológicas foram realizadas no Laboratório de Análise de Alimentos do Departamento de Ciências Agrárias da Unimontes (Universidade Estadual de Montes Claros), Campus Avançado de Janaúba, MG, Brasil.

No momento da abertura dos silos, o material foi homogeneizado e foram extraídos aproximadamente $200 \mathrm{ml}$ de suco da silagem com auxílio de uma prensa hidráulica para determinação dos valores de $\mathrm{pH}$ e nitrogênio amoniacal. Parte do material foi colocada em bandejas, pesada e posteriormente pré-seca em estufa de ventilação forçada a $55^{\circ} \mathrm{C}$ por $72 \mathrm{~h}$.

As amostras pré-secas foram moídas em moinho estacionário com peneira de $1 \mathrm{~mm}$ e, em seguida, foram submetidas a análises de MS e PB segundo a Helrich (1990). A partir do suco da silagem, foram determinados os valores de $\mathrm{pH}$ e os valores de nitrogênio amoniacal por destilação com óxido de magnésio (AOAC, 1990).

Já as avaliações in situ foram realizadas na fazenda experimental da Unimontes, localizada em Janaúba, MG, e as posteriores análises no Laboratório de Análise de Alimentos da mesma instituição.
Para a incubação in situ, foram utilizados quatro novilhos mestiços, fistulados no rúmen, com peso vivo médio de $450 \mathrm{~kg}$, alojados em baias com cochos e bebedouros individuais. Antes do experimento, os animais foram tratados contra endo e ectoparasitas. Cada animal recebeu diariamente silagem de sorgo (Volumas), água e uma mistura mineral comercial $a d$ libitum e $2 \mathrm{~kg}$ de concentrado à base de milho e de farelo de soja.

A composição bromatológica das silagens utilizadas no ensaio de degradabilidade in situ encontra-se na Tabela 1.

Os parâmetros da cinética de degradação ruminal in situ da MS e PB das silagens de sorgo foram estimados por meio da técnica dos sacos de náilon. Foram utilizados nesse procedimento sacos em náilon de 10 $\mathrm{cm} \times 20 \mathrm{~cm}$ com poros de 50 micras. Eles foram secos a $65{ }^{\circ} \mathrm{C}$ por $48 \mathrm{~h}$ e tiveram seus pesos registrados. Posteriormente, foram cheios com aproximadamente $5 \mathrm{~g}$ das silagens de sorgo estudadas, as quais foram previamente moídas a $5 \mathrm{~mm}$, correspondente a uma relação peso da amostra/área superficial do saco de náilon de $12,5 \mathrm{mg} \mathrm{cm}^{-2}$ (Nocek, 1988).

Foram colocados três sacos por tempo de incubação em cada animal, dentro do rúmen, nos seus

TABELA 1. Composição química e pH das silagens utilizadas no ensaio de degradabilidade (dados expresso na matéria seca).

\begin{tabular}{cccc}
\hline & CMSXS 165 & BR 700 & CMSXS 114 \\
\hline MS total (\%) & 28,22 & 32,66 & 31,02 \\
PB (\%) & 12,62 & 8,61 & 10,27 \\
FDN (\%) & 45,63 & 49,86 & 53,03 \\
FDA (\%) & 25,66 & 27,51 & 30,07 \\
Hcel (\%) & 19,96 & 22,35 & 22,36 \\
cel(\%) & 20,53 & 19,71 & 22,61 \\
Lignina (\%) & 5,13 & 7,80 & 7,46 \\
pH & 3,90 & 3,84 & 4,01 \\
$\mathrm{NH}_{3} / \mathrm{NT}(\%)$ & 4,28 & 4,01 & 5,89 \\
\hline
\end{tabular}


respectivos horários de incubação. Foram confeccionados três sacos/genótipo/animal/tempo, perfazendo um total de 252 sacos.

Os sacos com as amostras foram atados por uma borracha elástica a um aro metálico e presos a uma presilha de contenção e as mesmas ligadas a uma corda de náilon e a uma corrente de ferro que funcionou como âncora. Os sacos foram incubados no rúmen nos tempos de $6 \mathrm{~h}$, 12 h, 24 h, 48 h, 72 h e 96 h, seguindo o protocolo de incubação demonstrado na Tabela 2.

Nesse caso, as incubações foram realizadas seguindo a inversão do tempo, de tal forma que todos os saquinhos foram retirados do rúmen no final do período de fermentação.

Imediatamente depois de retirados do rúmen, os sacos foram imersos em água fria e posteriormente lavados, manualmente, em água corrente na temperatura ambiente até que a água se mostrou límpida. Após a lavagem, os sacos foram colocados em bandejas e levados à secagem em estufa de ventilação forçada por $48 \mathrm{~h}$ e transferidos para um dissecador durante 30 min e pesados. Após esse procedimento, o material restante nos sacos, de um mesmo genótipo, animal e período de incubação, foram transformados em "pool” homogêneo. Os resíduos de incubação foram moídos em moinho com peneira de $1 \mathrm{~mm}$ e utilizados para determinação de MS e PB (AOAC, 1990).

Os teores dessas frações nas amostras das forrageiras e dos resíduos de incubação, juntamente com os pesos dos materiais incubados e dos resíduos, foram utilizados para os cálculos do desaparecimento das respectivas frações. Os dados obtidos foram ajustados para uma regressão não linear pelo método de Gauss-Newton (Neter, et al., 1985), por meio do software SAS (SAS Institute, 1993), conforme a equação proposta por Orskov \& McDonald (1979);

TABELA 2. Protocolo de incubação e retirada dos sacos de náilon do rúmen.

\begin{tabular}{|c|c|c|c|c|c|c|}
\hline \multirow{2}{*}{ Animal } & & \multicolumn{5}{|c|}{ Dias } \\
\hline & Procedimento & $1^{\mathrm{o}}$ & $2^{\circ}$ & $3^{\circ}$ & $4^{\mathrm{o}}$ & $5^{\circ}$ \\
\hline \multirow{2}{*}{1} & Incubação & $96 \mathrm{~h}$ & $72 \mathrm{~h}$ & $48 \mathrm{~h}$ & $24 \mathrm{~h}$ & $12 / 6 \mathrm{~h}$ \\
\hline & Retirada & & & & & $6 / 12 / 24 / 48 / 72 / 96 \mathrm{~h}$ \\
\hline \multirow{2}{*}{2} & Incubação & $96 \mathrm{~h}$ & $72 \mathrm{~h}$ & $48 \mathrm{~h}$ & $24 \mathrm{~h}$ & $12 / 6 \mathrm{~h}$ \\
\hline & Retirada & & & & & $6 / 12 / 24 / 48 / 72 / 96 \mathrm{~h}$ \\
\hline \multirow{2}{*}{3} & Incubação & $96 \mathrm{~h}$ & $72 \mathrm{~h}$ & $48 \mathrm{~h}$ & $24 \mathrm{~h}$ & $12 / 6 \mathrm{~h}$ \\
\hline & Retirada & & & & & $6 / 12 / 24 / 48 / 72 / 96 \mathrm{~h}$ \\
\hline \multirow{2}{*}{4} & Incubação & $96 \mathrm{~h}$ & $72 \mathrm{~h}$ & $48 \mathrm{~h}$ & $24 \mathrm{~h}$ & $12 / 6 \mathrm{~h}$ \\
\hline & Retirada & & & & & $6 / 12 / 24 / 48 / 72 / 96 \mathrm{~h}$ \\
\hline
\end{tabular}




$$
\mathbf{Y}=\mathbf{a}+\mathbf{b}\left(\mathbf{1}-\mathbf{e}^{-\mathbf{c t}}\right)
$$

Em que:

$\mathrm{Y}=$ degradabilidade acumulada do componente nutritivo analisado, após um tempo t; $\mathrm{a}=\mathrm{in}-$ tervalo da curva de degradabilidade quando $\mathrm{t}=0$, correspondendo à fração solúvel do componente nutritivo analisado $; \mathrm{b}=$ potencial de degradabilidade da fração insolúvel do componente nutritivo analisado; a $+\mathrm{b}=$ degradabilidade potencial do componente nutritivo analisado, quando o tempo t não é um fator limitante; c = taxa de degradação por ação fermentativa da fração b.

Uma vez calculadas as constantes a, b e c, elas foram aplicadas à equação proposta por Orskov \& McDonald (1979);

$$
\mathbf{P}=\mathbf{a}+\frac{\mathbf{b} \cdot \mathbf{c}}{\mathbf{c}+\mathbf{k}}
$$

Em que:

$\mathrm{P}=$ degradabilidade ruminal efetiva do componente nutritivo analisado; $\mathrm{k}=$ taxa de passagem ruminal do alimento $\left(0,05 \% \mathrm{~h}^{-1}\right)$.

As degradabilidades efetivas ruminais foram calculadas e expressas em termos de matéria seca e proteína bruta efetivamente degradada no rúmen.

O delineamento experimental utilizado foi o inteiramente casualizado, com quatro repetições e quatro tratamentos. Os dados, quando significativos, foram submetidos à análise de variância. Os resultados foram submetidos à análise estatística utilizando-se o Sistema de Análises de Variância (Sisvar), descrito por Ferreira (2000) e, para a comparação de médias, utilizou-se o teste de Tukey ao nível de 5\% de significância, conforme o seguinte modelo:

$$
Y_{i j}: \mu+G_{i}+e_{i j}
$$

Em que:

$\mathrm{Y}_{\mathrm{ij}}=$ valor observado do genótipo i na repetição $\mathrm{j} ; \mu=$ média geral; $\mathrm{G}_{\mathrm{i}}=$ efeito do genótipo, com $\mathrm{i}=1,2$ e $3 ; \mathrm{e}_{\mathrm{ij}}=\mathrm{o}$ erro experimental associado aos valores observados $\left(\mathrm{Y}_{\mathrm{ij}}\right)$ que, por hipótese, tem distribuição normal com média zero e variância.

Nota-se, pela Tabela 3, que houve diferença $(p<0,05)$ em relação às concentrações das frações solúveis para todos os genótipos. A silagem da linhagem CMSXS 165 apresentou o maior valor para fração A (26,72\%), estando de acordo com a maior taxa de degradação deste material (7,75\%). Quanto maiores a fração solúvel e o potencial de degradação de um alimento, maior será sua taxa de degradação.

Os resultados encontrados da fração A estão próximos aos relatados por Molina et al. (2002) avaliando seis genótipos de sorgo com e sem tanino, que encontraram valores de 15,14 a 23,01\%. Segundo Tonani et al. (2001), o desaparecimento da fração A caracteriza a solubilização dos açúcares e dos compostos nitrogenados solúveis remanescentes da fermentação no silo, constituída, principalmente, de sacarose, frutose, glicose e pequenas quantidades de manose e galactose.

A fração insolúvel potencialmente degradável (B) da matéria seca ficou entre 43,43 e 53,83\%, e o maior valor encontrado foi para a silagem da linhagem BR 700, sendo que todas as silagens foram diferentes entre si $(\mathrm{p}<0,05)$. 
TABELA 3. Fração solúvel (A), fração insolúvel potencialmente degradável (B), taxa de degradação (C), fração indigestível (Fi), degradação potencial (Dp), degradação efetiva (De) da matéria seca das silagens de três genótipos de sorgo.

\begin{tabular}{|c|c|c|c|c|}
\hline \multirow{2}{*}{ Parâmetros } & \multicolumn{3}{|c|}{ Genótipos $^{1}$} & \multirow{2}{*}{$\mathrm{CV}(\%)$} \\
\hline & CMSXS 165 & BR 700 & CMSXS 114 & \\
\hline $\mathrm{A}(\%)$ & $26,72 \mathrm{a}$ & $15,18 \mathrm{~d}$ & $20,82 \mathrm{~b}$ & 2,13 \\
\hline B $(\%)$ & $45,89 \mathrm{c}$ & $53,83 \mathrm{~b}$ & $43,43 d$ & 1,14 \\
\hline $\mathrm{C}\left(\% \mathrm{~h}^{-1}\right)$ & $7,75 \mathrm{a}$ & $5,75 \mathrm{~b}$ & $5,25 \mathrm{bc}$ & 11,23 \\
\hline $\mathrm{Fi}(\%)$ & $27,37 \mathrm{c}$ & $30,98 \mathrm{~b}$ & $35,74 \mathrm{a}$ & 1,11 \\
\hline Dp (\%) & $72,62 b$ & $69,01 \mathrm{c}$ & $64,26 \mathrm{~d}$ & 0,47 \\
\hline De $(\%)$ & $54,58 \mathrm{a}$ & $44,01 \mathrm{~b}$ & $43,13 b$ & 2,45 \\
\hline
\end{tabular}

${ }^{1}$ Médias seguidas pela mesma letra nas linhas, não diferem entre si $(\mathrm{p}>0,05)$, pelo teste de Tukey.

Quanto à taxa de degradação da MS, a silagem da linhagem CMSXS 165 foi superior $(\mathrm{p}<0,05)$ a todos os tratamentos. O híbrido BR 700 foi semelhante $(\mathrm{p}>0,05)$ ao CMSXS 114. Esses resultados são condizentes com os observados em silagem de boa qualidade.

Segundo Sampaio (1994), taxas de degradação da matéria seca inferiores a $2 \%$ por hora indicam alimentos de baixa qualidade, pois necessitam de longo tempo de permanência no rúmen para serem degradados.

Quando comparadas as linhagens isogênicas, o maior valor da fração indigestível Fi foi para a silagem da linhagem CMSXS 114 $(35,74 \%)$ e o menor valor para CMSXS 165 $(27,37 \%)$. Essa diferença sugere que os taninos comprometem a digestibilidade das silagens que os contêm.
O maior valor observado de degradabilidade potencial (DP) foi para a silagem do sorgo sem tanino CMSXS 165. Entretanto, degradabilidade potencial superior à observada nesta pesquisa foi relatada por Molina et al. (2003) para silagens de sorgo BR 700 (76,41\%). Essas diferenças podem ser atribuídas aos estádios de maturação do sorgo na ensilagem e na proporção de colmo, folhas e grãos da matéria ensilada.

Com relação à taxa de degradação efetiva da matéria seca, nota-se que a silagem da linhagem CMSXS 165 sem tanino foi superior $(p<0,05)$ a todos os tratamentos e, ao se compararem as duas linhagens isogênicas CMSXS 165 e CMSXS 114, verificase que as diferenças encontradas podem ser atribuídas aos taninos, já que os mesmos podem influenciar na degradabilidade da MS. Sousa (2001) justifica o efeito deletério do tanino sobre a digestibilidade da 
MS como sendo originado de: inibição das enzimas digestivas microbianas; inibição do crescimento microbiano; indisponibilização do substrato para a microbiota ruminal, através da formação de complexo substrato-tanino insolúvel. sem tanino apresentou maior fração potencialmente degradável quando comparada à silagem da linhagem CMSXS 114 com tanino, sugerindo que os taninos comprometem a degradação da $\mathrm{PB}$ nas silagens que as contenham.

TABELA 4. Fração solúvel (A), fração insolúvel potencialmente degradável (B), taxa de degradação (C), fração indigestível (Fi), degradação potencial (Dp), degradação efetiva (De) da proteína bruta das silagens de quatro genótipos de sorgo com e sem tanino nos grãos.

\begin{tabular}{lcccc}
\hline & \multicolumn{3}{c}{ Genótipos $^{1}$} \\
Parâmetros & CMSXS 165 & BR 700 & CMSXS 114 (\%) \\
\cline { 2 - 4 } A (\%) & $24,73 \mathrm{a}$ & $16,64 \mathrm{~d}$ & $22,45 \mathrm{c}$ & 2,22 \\
B (\%) & $45,12 \mathrm{a}$ & $40,35 \mathrm{~b}$ & $40,97 \mathrm{~b}$ & 0,96 \\
C (\%/h) & $12,50 \mathrm{a}$ & $7,50 \mathrm{~b}$ & $6,50 \mathrm{~b}$ & 7,16 \\
Fi (\%) & $30,13 \mathrm{~d}$ & $43,00 \mathrm{a}$ & $36,56 \mathrm{c}$ & 1,04 \\
Dp (\%) & $69,86 \mathrm{a}$ & $56,99 \mathrm{~d}$ & $63,43 \mathrm{~b}$ & 0,61 \\
De (\%) & $56,98 \mathrm{a}$ & $40,67 \mathrm{~d}$ & $45,66 \mathrm{~b}$ & 1,37 \\
\hline
\end{tabular}

${ }^{1}$ Médias seguidas pela mesma letra nas linhas, não diferem entre si $(\mathrm{p}>0,05)$, pelo teste de Tukey.

Similar ao ocorrido com a matéria seca, o genótipo CMSXS 165 apresentou a maior fração solúvel da $\mathrm{PB}$, que foi de $24,73 \%$, sendo superior ( $\mathrm{p}<$ $0,05)$ a todos os tratamentos (Tabela 4). Esses resultados foram semelhantes aos encontrados por Molina et al. (2003), que verificaram solubilidades da PB $\left(\mathrm{t}_{0}\right)$ variando de 19,55 a 23,01\%, e por Serafim et al. (2000), que registraram valores médios de $23 \%$ para o mesmo parâmetro ao avaliarem silagens de híbridos de sorgo.

Para as frações insolúveis potencialmente degradáveis (B), foram obtidos valores que variaram de 38,71 a 45,12\%. A silagem da linhagem CMSXS 165
Comportamento semelhante foi observado para a fração indigestível em que a silagem da linhagem CMSXS 165 sem tanino apresentou menor fração indigestível que a silagem da linhagem CMSXS 114 com tanino, reforçando a sugestão de que os taninos comprometem a digestão de PB nas silagens em que estes compostos fenólicos estejam presentes.

A maior taxa de degradação (C) foi obtida pela silagem do CMSXS $165\left(12,50 \% \mathrm{~h}^{-1}\right)$, seguida pela silagem do híbrido BR $700\left(7,50 \% \mathrm{~h}^{-1}\right)$ e $6,50 \%$ $\mathrm{h}^{-1}$ para CMSXS 114. Esses valores encontrados estão acima do proposto por Sampaio (1988), que seria de 2 
a $6 \%$ para a maioria dos alimentos vegetais. Contudo, as taxas de degradação foram em média superiores àquelas obtidas por Campos et al. (2003), que variaram de $\left(1,0\right.$ a $\left.1,7 \% \mathrm{~h}^{-1}\right)$ para silagens de sorgos com e sem tanino.

Os resultados de potenciais de degradação da PB obtidos neste experimento foram semelhantes aos verificados por Pires et al., (2009), que encontrou resultados de $(79,88 \%)$ para a silagem da linhagem CMSXS 165 sem tanino, sendo seguida pelo CMSXS 114 (66,44\%), BR 601 (63,60\%) e BR $700(55,31 \%)$. E inferiores aos obtidos por Martins et al. (1999), que foram de 37,30\% para silagens de sorgo.

O genótipo da linhagem isogênica sem tanino CMSXS 165 apresentou maior degradabilidade efetiva do que a linhagem com tanino CMSXS 114. Os resultados obtidos indicam que existe efeito negativo do tanino sobre a degradabilidade da PB. Essa menor degradação da PB da linhagem CMSXS 114 provavelmente deveu-se à presença de taninos, os quais se ligam à fração nitrogenada, podendo esse complexo tornar-se um componente do resíduo da FDA (Campos et al., 2003).

A presença de tanino em genótipos de sorgo pode reduzir a degradabilidade ruminal da MS e da PB. A linhagem CMSXS 165 apresentou melhor degradabilidade ruminal.

\section{Agradecimentos}

À Fapemig (Fundação de Apoio à Pesquisa do Estado de Minas Gerais) o apoio financeiro e à Capes (Coordenação de Aperfeiçoamento de Pessoal de Nível Superior) a bolsa de Mestrado concedida.

\section{Referências}

HELRICH, K. Official methods of analysis of the Association of Official Analytical Chemists. 15. ed. Arlington, 1990. v.1, 1117 p.

CABRAL FILHO, S. L. S. Efeito do teor de tanino do sorgo sobre a fermentação ruminal e parâmetros nutricionais em ovinos. 2004. 88 f. Tese (Doutorado em Ciências) - Escola Superior de Agricultura "Luiz de Queiroz”, Universidade de São Paulo, Piracicaba.

CAMPOS, W. E.; SATURNINO, H. M.; SOUSA, B. M.; BORGES, I.; GONCALVES, L. C.; FERREIRA, P. M.; CARVALHO, A. U. Degradabilidade in situ da silagem de quatrogenótipos de sorgo com e sem tanino. I. Matéria seca e proteína bruta. Arquivo Brasileiro de Medicina Veterinária e Zootecnia, Belo Horizonte, v. 55, p. 209-215, 2003.

FERREIRA, D. F. Sistema de análises de variância para dados balanceados. SISVAR 4.1. Lavras: UFLA, 2000. Pacote computacional.

MOLINA, L. R.; RODRIGUEZ, N. M.; GONÇALVES, L. C.; BORGES, I.; SOUSA, B. M.; LARA, A. C. Degradabilidade in situ da matéria seca e da proteína bruta das silagens de seis genótipos de sorgo (Sorghum bicolor (L.) Moench), com e sem tanino no grão, ensilados no estádio de grão farináceo. Revista da Faculdade de Medicina Veterinária e Zootecnia da USP, São Paulo, v. 39, n. 5, p. 233-237, 2002.

NETER, J.; WASSERMAN, W.; KUTNER, M. H. Linear statistical models: regression, analysis of variance, and experimental designs. 2. ed. Homewwod:Richard D. Irwin, 1985. 112 p.

NEUMANN, M.; RESTLE, J.; ALVES FILHO, D. C.; BERNARDES, R. A. C.; ARBOTlE, Z.; CERDOTES, L.; PEIXOTO, L. A. de O. Avaliação de diferentes híbridos de sorgo (Sorghum bicolor, L. 
Moench) quanto aos componentes da planta e silagens produzidas. Revista Brasileira de Zootecnia, Viçosa, MG, v. 31, n. 1, p.302-312, 2002.

NOCEK, J. E. In situ and other methods to estimate ruminal protein andenergy digestibility: a review. Journal Dairy Science, Champaign, v. 71,n. 8, p. 2051-2069, 1988.

ORSKOV, E. R.; McDONALD, I. The estimation of gedradability in the rúmenform incubation measurement weighted according to rate of passage. Journalof Agricultural Science, Cambridge, v. 92, n. 1, p. 499-508, 1979.

PIRES, D. A. de A.; GONÇALVES, L. C.; RODRIGUES, J. A. S.; JAYME, D. G.; GUIMARAES JUNIOR, R.; RODRIGUEZ, N. M.; BORGES, I.; BORGES, A. L. C. C.; JAYME, C. G.; BOTELHO, P. R. F.; LIMA, L. O. B. Degradabilidade in situ das frações fibrosas da silagem de sorgo. Revista Brasileira de Milho e Sorgo, Sete Lagoas, v. 8, n. 2, p. 175-185, 2009.

SAMPAIO, I. B. M. Experimental designs and modeling techniques in the study of roughage degradation in rumen and growth of ruminants. 1988. $214 \mathrm{f}$. Tese (Doutorado em Fisiologia) - University of Reading, Reading.

SAMPAIO, I. B. M. Contribuições estatísticas e de técnica experimental para ensaios de degradabilidade de forragens quando avaliada in situ. In: SOCIEDADE BRASILEIRA DE ZOOTECNIA， REUNIÃO ANUAL, 31., 1994, Maringá. Anais... Maringá: Sociedade Brasileira de Zootecnia, 1994. p. 81-88.

SAS INSTITUTE. SAS/STAT user's Guide: statistics, version 6. 4. ed. Cary, 1993. v. 2, 943 p.

SERAFIM, M. V.; BORGES, I.; GONCALVES, L. C.; RODRIGUES, N. M.; RODRIGUES, J.A.S. Desaparecimento in situ da matéria seca, proteína bruta e fração fibrosa das silagens de híbridos de sorgo (Sorghum bicolor (L.) Moench). Arquivo Brasileiro de Medicina Veterinária e Zootecnia, Belo Horizonte, v. 52, p. 634-640, 2000.

SOUZA, B. M. Degradabilidade in situ dos componentes nutricionais das silagens de três genótipos de sorgo (CMSXS 180, CMSXS 227 e BR 700). 2001. 36 f. Dissertação (Mestrado em Zootecnia) - Escola de Veterinária, UFMG, Belo Horizonte.

TONANI, F. L.; RUGGIERI, A. C.; QUEIROZ, A. C.; ANDRADE, P. Degradabilidade ruminal in situ da matéria seca e da fibra em detergente neutro em silagens de híbridos de sorgo colhidos em diferentes épocas. Arquivo Brasileiro de Medicina Veterinária e Zootecnia, Belo Horizonte, v. 53, p. 100-104, 2001. 